\title{
Business and Environment Performance Evaluation in Supply Chains: A Formal Model-Driven Approach
}

\author{
Gabriel Alves Jr., Paulo Maciel, Ricardo Lima and Fábio Magnani \\ Federal Univestity of Pernambuco, Recife-PE, \\ Brazil
}

\section{Introduction}

While economic and service level indicators were adequate to show the performance of supply chains (SCs) in the past, nowadays, environment indicators are gradually becoming more relevant (Beamon, 1999). Many prominent companies and academic research groups around the world are making efforts to provide environmentally responsible products and services. These topics are subjects of intensive study not only due to the respective impact of the production and transport systems in our planet but also particularly related to the image these companies aim to project to the society (Beamon, 1999; Srivastava, 2007). Moreover, supply chains' managers must carry about optimizing an endless number of variables that might impact costs and operational performance. These variables usually get in conflict between themselves. For instance, increasing the amount of stored goods might reduce the lead time to customers, but also increase storage costs and environment impacting resources like energy. Modelling is quite often employed for quantitative analysis of SCs (Simchi-Levi et al., 2000). One of the main advantages in use modelling techniques is the possibility of analyse "what-if" questions. Thereby, it is possible to evaluate different scenarios looking for the most optimized ones. Although the strict mathematical modelling is one of the most used approaches in the evaluation of SCs (Cohen \& Lee, 1988; Sabri \& Beamon, 2000; Simchi-Levi et al., 2005), it is not always the best option. Such a method requires some simplifications that might incur inaccurate results. Other modelling techniques, like queueing networks (Gross, 2009), Markov Chains (Norris, 1998), and Petri Nets (Bolch et al., 2006; Desrochers \& Al-Jaar, 1994; Jensen, 1997), might be adopted so as to overcome this problem.

Petri nets were proposed by Carl Adam Petri in 1962 (Petri, 1962), and have evolved into a formalism employed in different areas such as informatics, electronics and chemistry since then. This modelling technique has a graphical representation that supports the specification and design of systems. Having a solid mathematical foundation, Petri nets are very well suited for the numerical evaluation of complex systems. Different extensions were proposed to this formalism, including the concept of time (Ramchandani, 1994) after Carl Petri's initial work. Petri nets have been already adopted for evaluating manufacturing systems and SCs (Alves et al., 2010; Desrochers \& Al-Jaar, 1994; Makajic-Nikolic et al., 2004; Silva \& Maciel, 2005; Viswanadham \& Raghavan, 2000). Stochastic Petri nets (SPNs) (Bolch et al., 2006; German, 1994; Haas, 2002; Marsan et al., 1995) deals with probabilistic distributed times, which are approximated to distribution functions like exponential, Erlang and uniform. 
The framework that is going to be presented in this chapter uses stochastic reward nets (SRNs) (Bolch et al., 2006), which are a specific type of SPN, for modelling and evaluating SCs. The SCs are modelled using a bottom-up approach, based on pre-defined components (Alves et al., 2010), that model specific entities and processes of the real system, focusing on the product/information flows. This approach allows using SRNs as the modeling technique even without further knowledge on it. This is advantageous for industrial users that are not familiar with Petri nets.

The library of models allows making experiments by changing variables like the transportation and production delays, supply chains' facilities relationship, replenishment policies and energy sources. The component-based modelling together with a well-defined composition process guarantee that the final model will have some desired Petri net properties (Murata, 1989). A numerical solution based on the continuous-time Markov chain (CTMC) (Bolch et al., 2006; Norris, 1998) is thus possible, either for obtaining transient or steady state solutions. The component-based modeling tackles the requirement of verifying the model's correctness. However, a validation of the model might still be required. While the the components guarantee that the structure of the systems will be correctly represented in the Petri net notation, there is no guarantee that the model's parameters (e.g. mean time between failures and tasks delays) were assigned correctly in the model.

Finally, this chapter will depict how to use a single model to assess business and environment indicators. This facet helps on evaluating possible business and environment trade-offs. Besides, we will show the advantage of using the exergy concept (Kotas, 1985; Szargut et al., 1988) to quantify the impact of alternative energy sources.

The remainder of this chapter is organized as follows. Section 2 presents a brief introduction to supply chains and sustainability. Some models that are usually adopted when evaluating performance of systems are discussed in section 3. This section will be focused on SRNs, since the proposed framework uses this model. Section 4 details metrics, evaluation process of the framework. The library of models is presented in section 5. Section 6 shows a case study conducted using the framework. Finally, concluding remarks are done in section 7.

\subsection{Related works}

A brief review of some related works is now going to be presented. An approach for modeling logistics networks based on high-level timed colored Petri nets is proposed in van der Aalst (1992). Some components are proposed to model supply chain entities, and analysis methods are proposed for this kind of Petri nets. However, time is associated with tokens and represented by an interval specified by its lower and upper bounds in this type of model, making it hard to follow the natural association of time to activity delays (transitions) as followed in most other timed Petri nets.

Stochastic colored Petri nets are used to model and evaluate logistics systems in Zimmermann (2007); Zimmermann et al. (2007). In such colored Petri nets, the metrics are almost often computed through the simulation of a program resulting from the model specification. Another kind of Petri nets, called Batch Deterministic Stochastic Petri Nets (BDSPN), is proposed in Chen et al. (2005) to model and evaluate supply chains. It extends Deterministic and Stochastic Petri nets (DSPNs) (Marsan \& Chiola, 1987) including batch places and tokens. Few works have followed using this kind of net so far (Labadi et al., 2007). Using such nets is unfeasible due to the lack of supporting tools.

In Viswanadham \& Raghavan (2000), the authors evaluate a supply chain considering make-to-stock (MTS) and assembly-to-order (ATO) policies. To achieve their goals, authors 
consider that operations occur in pipeline and not in parallel such as in most supply chains. A multi-echelon make-to-stock supply chain is evaluated in Raghavan \& Roy (2005) using Stochastic Petri Nets.

One of the few proposals for performance evaluation of supply chains with SPN modules is presented in Dotoli \& Fanti (2005). The entities and flows are represented through the composition of these modules, but such process requires some changes on basic models. Although the use of modules supports the supply chain modeling, the lack of a well-defined composition process restrains an automatic parsing from a high-level representation into an SPN model.

Inventory management of supply chain nodes is closely related to distribution strategies. The inventory replenishment policy of intermediary entities significantly influences the overall supply chain's QoS. A well-known problem that can occur in a supply chain is the Bullwhip Effect (Lee et al., 1997). The Beer Game (Lee et al., 1997; Simchi-Levi et al., 2000) aims at representing such a problem. Makajic-Nikolic et al. (2004) model this game via a timed hierarchical colored Petri Net (Jensen, 1997). The work also conducts experiments to evaluate the impact of different replenishment strategies over individual participants and the entire supply chain.

An extensive state-of-the-art review for the green supply chain management is presented in Srivastava (2007). The author classifies the existent works about green supply chains (GrSCs) according to the sub-areas of this discipline and the used evaluation technique. Some of the classified sub-areas are: products manufacturing and remanufacturing, life cycle assessment (LCA), reverse logistics, network design, and waste management. Regarding the technique used, the author classifies works from empirical methods to the mathematical modeling, including the linear programming (Louwers et al., 1999), queueing theory (Guide et al., 2005; van der Laan et al., 1996), Markov chains (MCs) (Fleischmann et al., 2002; van der Laan \& Salomon, 1997), and Petri nets (Moore et al., 1998).

Veleva proposes a methodology for monitoring and evaluating indicators in sustainable production systems (Veleva \& Ellenbecker, 2001). The author determines a five-level evaluation system, where different sustainability indicators are addressed by each level. The first level checks the compliance to standards and laws. The second level assess the performance of the consumption and disposal of resources. The third level is concerned about the effects of the system over workers, public health and environment. The fourth level the evaluation goes beyond the system boundaries, checking the product life cycle and the supply chain impacts on environment. Finally, the fifth level evaluation measures indicators regarding the impacts of the system on the economy, society and environment of the local (where the company is located) and global (where the company sells its products) communities.

The Life Cycle Assessment (LCA) is a well known method for evaluating the environment impacts owing to the product existence (Cascio, 1999; Heijungs et al., 1992; ISO, 2006). Currently, there are some commercial tools used for LCA (e.g. GaBi (GaBi Software - product sustainability, 2010) and SimaPRO (SimaPRO LCA Software, 2010)). Within these tools, metrics like the Global Warming Potential (GWP) (IPCC, 2001) are estimated based on a conversion database of resources' consumption. Nevertheless, these tools are not well suited to conduct a performance evaluation of the activities involved in the product life cycle (e.g. machines utilization, reliability analysis), since it is not adressed by LCA. 
The exergy analysis have also been employed to measure and compare the use of different energy sources in systems and processes (Oliveira Filho, 1995). This kind of analysis aims at comparing the energetic efficiency and destruction considering the Second Law of Thermodynamics (Kotas, 1985).

Some efforts have also been made with the objective of combine exergy and LCA. These efforts have resulted in evaluation methods like the Exergetic Lyfe Cycle Assessment (ELCA) (Cornelissen \& Hirs, 2002) and the Lyfe Cycle Exergy Analysis (LCEA) (Gong \& Wall, 2001). These methods have been employed in different areas like electricity production (Rosen \& Dincer, 2003), supply chains (Apaiah et al., 2006), and IT companies (Lettieri et al., 2009).

\section{Green supply chains}

This section provides a brief introduction to some sustainability issues in supply chains. The beginning of this section describes some traditional approaches that are usually used when assessing sustainability in supply chains. Section 2.1 presents the exergy concept and its applications in the field of sustainability.

A supply chain (SC) manager must carry out all the activities necessary for producing and delivering goods to customers. Acquisition of raw materials, manufacturing, assembling and transportation are some of those activities. The Green Supply Chain (GrSC) extends the supply chain by considering the backward flow and the environment impacts of the SC's activities. The backward flow is known as reverse supply chain. The GrSC schema is presented in Figure 1, which was adapted from Beamon (1999) and Cash \& Wilkerson (2003).

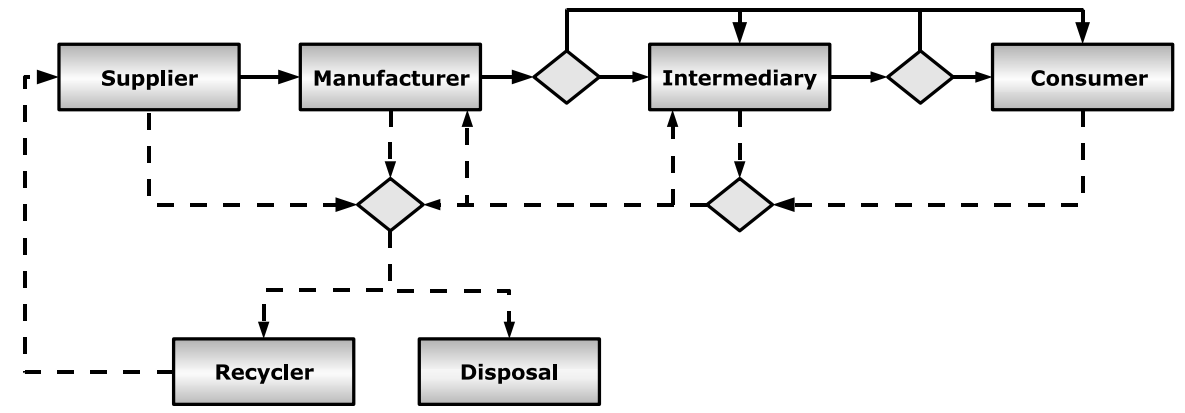

Fig. 1. Green Supply Chain schema.

Regarding the schema of Figure 1, the dashed lines represents the reverse flow of the green supply chain (Beamon, 1999; Cash \& Wilkerson, 2003). The self-loop in the intermediary was included to represent a n-level supply chain (Simchi-Levi et al., 2000), that can have several intermediaries (e.g. distributors and wholesalers). Each line represents the movement of goods, which might include the transportation activity. The "disposal" rectangle represents the final disposal of the goods in landfills or for composting.

Several organizations moved towards the proposal of practices and management techniques that could help companies to provide environmentally conscious products and services. The International Organization for Standards (ISO) developed the ISO 14000 series standard with this objective (Cascio, 1999; ISO, 2006). Environmental management systems (EMS), environmental performance evaluation (EPE), and life cycle assessment (LCA) are some of the areas covered by this series. This chapter will be focused on EPE and LCA. 
The ISO 14031 provides guidelines for the selection and use of environment performance indicators (EPIs) in the EPE of organizations. This standard defines an EPI as and expression that is used to provide information about environmental performance or the condition of the environment. The EPIs can be expressed as relative or absolute measurements and can also be aggregated and/or weighted. These indicators can be classified as: Absolute indicators are directly obtained from an input-output analysis. Relative indicators are expressed as a reference to other variables like the production in tons, number of employees, etc. Indexed indicators are expressed as a percentage with respect to a total, or a percentage change to previously assessed values. Aggregated indicators sums indicators that have the same unit, which are assessed over more than one production stage. Weighted indicators assigns different weights to assessed variables of a productions stage depending on its importance.

Absolute EPIs must be used carefully. An increment on the demand or production of a company almost often incurs in an expected increment on these indicators. For instance, increasing the production implies an increment on the consumption of raw materials. In such a sense, relative indicators are usually more accurate to depict the environment performance than absolute indicators. Following are some examples of EPIs (Beamon, 1999; Cascio, 1999): relative/absolute quantity of specific pollutant emitted (e.g. $\mathrm{CO}_{2}, \mathrm{SO}_{2}$, CFCs); relative/absolute quantity of hazardous substances emitted; relative/absolute $k W h$ of electricity consumed; relative/absolute amount of waste produced; percent of raw materials from renewable resources; percent of waste recycled; investment in environmental programs; amount of regulatory violations or fines; number of environmental incidents/acidents.

A life cycle assessment (LCA) intends to measure the social, environmental and economical impacts of a product or service (Cascio, 1999; ISO, 2006). This assessment must be accounted for the extraction/production of raw materials, manufacture, distribution, use, and disposal including the transportation necessary for any of the stages of the product's life cycle. LCA can be conducted for a single product or for an entire company. Regarding the boundaries of the LCA, it can be classified as follows:

gate-to-gate: looks at a single value-added process in the entire supply chain;

cradle-to-gate: looks at the product life cycle from raw materials and manufacture ("cradle") until the product leave the factory's gate;

cradle-to-grave: beyond that steps considered in the cradle-to-gate, this type of LCA considers the remaining life cycle until the disposal of the product;

cradle-to-cradle: beyond that steps considered in the cradle-to-grave, this type of LCA considers reverse and recycling processes of the product;

The framework presented in this chapter uses the gate-to-gate LCA. This type of LCA can be composed for each stage of the supply chain in order to achieve a complete LCA. One of the units that can be used in the LCA is the Global Warming Potential (GWP). It was proposed by the Intergovernmental Panel on Climate Change (IPCC) in order to allow comparing the radiative effect of different substances considering a time horizon (IPCC, 2001). The $\mathrm{CO}_{2}$ equivalent $\left(\mathrm{CO}_{2} e\right.$ or $\mathrm{CO}_{2} \mathrm{Eq}$.) is the unit that measures the GWP. It expresses the radiative effect of a substance considering the GWP of the $\mathrm{CO}_{2}$ as reference (DEFRA - Department for Environment, Food and Rural Affairs, 2009; Frischknecht et al., 2005; IPCC, 2001). The GWP of the $\mathrm{CO}_{2}$ is thus 1 . The framework presented in this chapter will be focused on the GWP measurement, despite of other environment impacts like noise, acidification, and desertification. 


\subsection{Exergy and sustainability}

The Second Law of Thermodynamics (SLT) asserts that there will always be loss of quality when converting a type of energy into another type. The concept of exergy is linked to the SLT, since it assess the amount of energy that can be converted into useful work, that means the quality of the energy (Kotas, 1985; Szargut et al., 1988). Because of that available energy, available work or simply availability, are also synonyms of exergy. The amount of energy that is not available is called anergy (Sato, 2004).

Let $E, X$ and $A$ be the respective amounts of energy, exergy and anergy, thus the equation $E=X+A$ depicts the relation between these amounts. Such a relation can also be expressed as in Equation 1, by using an energy efficiency factor $\alpha$.

$$
X=\alpha E \therefore A=(1-\alpha) E
$$

Let $X_{\text {in }}, X_{\text {out }}, X_{\text {diss }}$ and $X_{\text {dest }}$ be the amount of input, output, dissipated and destroyed exergy in a process. Since $X_{\text {dest }}=\left(1-\eta_{I I}\right) X_{\text {in }}-X_{\text {diss }}$, where $\eta_{I I}$ is the exergetic efficiency of the process, the SLT is mathematically represented by Equation 2.

$$
X_{\text {in }}=X_{\text {out }}+X_{\text {diss }}+X_{\text {dest }} \therefore \eta_{I I}=\frac{X_{\text {out }}}{X_{\text {in }}}
$$

The chemical exergy $x_{c h}$ of a material can be calculated in function of its mass composition (Kotas, 1985). It represents the amount of useful energy in any kind of material, including energy sources. Equation 3 depicts the total chemical exergy $X$ (in $\mathrm{kJ}$ ) for a mass $m$ (in $\mathrm{kg}$ ) of a material whose chemical exergy is depicted by $x_{c h}$ (in $\mathrm{kJ} / \mathrm{kg}$ ). The physical and chemical exergies fully defines the total exergy of a system. Thereby, Equation 4 expresses the exergy of a system with kinetic energy $k e$, potential energy pe, enthalpy $h$, entropy $s$ and $j$ elements in its chemical composition, at a reference environment with enthalpy $h_{0}$, entropy $s_{0}$, and temperature $T_{0}$. Considering that the system is in physical equilibrium with the reference environment, the total exergy is its chemical exergy.

$$
\begin{gathered}
X_{c h}=m x_{c h} \\
X=k e+p e+\left[\left(h-h_{0}\right)-T_{0}\left(s-s_{0}\right)\right] m+\sum_{j} X_{c h, j}
\end{gathered}
$$

Szargut et al. (2005) proposes several values for the chemical exergy of chemical elements. These values were calculated based on a reference environment, which the authors claim to become an international reference for evaluating the natural resources on Earth. These values can be used in order to calculate the chemical exergy of any resource of a supply chain, including waste and raw materials. Although, it might be cumbersome to identify the exact chemical composition of each material used in the supply chain. To overcome this problem, some authors proposes approximations to calculate the chemical exergy of wasted materials (Ayres et al., 1998). Despite of this, using exergy for any sort of resources is a awkward task. There are several proposals that consider the exergy analysis for measuring sustainability performance. Extended Exergy Account (EEA) (Sciubba, 2003), Cumulative Exergy Consumption (CEC) (Szargut \& Morris, 1985), Life Cycle Exergy Analysis (LCEA) (Gong \& Wall, 2001), Exergetic Life Cycle Assessment (ELCA) (Ayres et al., 1998; Cornelissen \& Hirs, 2002) are some of these approaches, which usually measure the amount of exergy consumed, or destroyed, in a process. Thus, the less exergy a process consumes, or destroys, the most sustainable it is. Some proposals also joins exergy, cost and 
other aspects to provide a general insight of the analysed process (Rosen \& Dincer, 2003; Sciubba, 2003).

The life cycle exergy analysis (LCEA) (Gong \& Wall, 2001) aims at measuring the total input and output exergy in the product life cycle, also differing renewable and non-renewable resources. It divides a system in three stages: construction, operation, and clean up. In the construction and clean up stages, the system indirectly consumes exergy $\left(E_{\text {indirect }}\right)$. During the operation the system indirectly consumes exergy for its maintenance $\left(E_{\text {indirect }}\right)$ and directly consumes it in order to produce finished goods $\left(E_{i n}\right)$. Besides, the finished good also has an amount of exergy $\left(E_{p r}\right)$.

When the system uses non-renewable resources, there will be a degradation of such resources, thus $E_{p r}<E_{\text {indirect }}+E_{i n}$. When renewable resources are used, the LCEA does not consider the input exergy of these resources. Thus, in a time $t_{\text {payback }}$, all the exergy that was indirectly consumed will be compensated by the product. In this case the net exergy product $\left(E_{n e t, p r}\right)$, is the amount of exergy generated beyond $t_{\text {pay back }}$ and is measured as: $E_{n e t, p r}=E_{p r}-E_{\text {indirect }}$. The exergetic life cycle assessment (ELCA) (Cornelissen \& Hirs, 2002), aims at measuring the exergy destruction due to the irreversibility of processes, quantifying the depletion of natural resources. The ELCA allows expressing the resources depletion when renewable resources are not used. But, even when these resources are used, a high irreversibility may represent an inefficient consumption of these resources. In such a sense, the depletion of non-renewable resources is measured by subtracting the exergy from renewable resources from the total irreversibility of the system, as: $D_{\text {natural resource }}=I_{\text {life cycle }}-E_{\text {renewables, }}$, where $I_{\text {life cycle }}$ is the total irreversibility in the process life cycle and $E_{\text {renewables }}$ is the amount of exergy from renewable resources. Besides, the irreversibility of each process as measured as $I=$ $X_{\text {out }}-X_{i n}$, where $X_{o u t}$ and $X_{i n}$ are the respectives output and input chemical exergy of each process.

Due to the difficulty in obtaining reliable exergetic values for any sort of material (Ayres et al., 1998), we adopt the exergy analysis (LCEA) just for resources that are consumed for energetic purposes. The GWP analysis (LCA) is used for the other resources instead. Furthermore, the LCEA provides reliable results when comparing the environment impacts of using different energy sources. Such an approach supports the evaluation of "what-if" questions when conducting an EPE without increasing the complexity of this activity.

\section{Performance models}

This section aims at providing some insights about different evaluation methods that are often used when measuring systems performance. A performance evaluation model aims at representing a real system, through mathematical or simulation methods, in order to assess measures. Experiments that can be easily conducted in a model could be hardly, or even impossible, to be done in the real system. The evaluation model can be grouped into: analytical, numerical, and simulation. These methods will be discussed in the following subsections.

\subsection{Analytical solution}

Analytical solution methods try to represent the real system using mathematical expressions. This kind of solution is well-suited for simple systems. Although, the complexity of a real system can forbid an analytical solution. There are several manners of analytically representing a system. In the specific case of supply chains there are models to evaluate problems like that ones related to inventory replenishment policies (Ballou, 2004; 
Simchi-Levi et al., 2000), the logistics network (Narahari \& Biswas, 2007; Simchi-Levi et al., 2005), and also to support the decision making based on different variables (e.g. cost, service level, environment) (Louwers et al., 1999). But, these methods tend to make several simplifications. For instance, defining the best lower inventory level of a facility in a multi-echelon supply chain can be cumbersome using analytical models.

Queueing theory (Gross, 2009) is an analytical method that was adopted in different areas, including supply chains (Guide et al., 2005; van der Laan et al., 1996). This method aims at representing systems through queues. A queue system is represented by 6-tuple $A / S / m / B / N / S D$, where $A$ is the interval between arrivals, $S$ is the service time, $m$ is the number of servers, $B$ is the maximum size of the queue, $N$ is the population (can be infinity) and $S D$ is the service policy of the system. The times related to $A$ and $B$ can follow distributions like the Erlang, exponential, deterministic, etc. Service policies related to $S D$ can be, for instance, First-Come-First-Served, Last-Come-First-Served, Round Robin, and Infinite Server.

The queue theory allows assessing metrics like servers utilization, system's throughput, response and waiting times, which are the time that a task spent in the system and that it waits before being processed, queue length, and the amount of tasks in the system. For instance, considering that orders (tasks) arrive to a factory (server) with a given interval (rate), the queue theory can provide measures like, the amount of orders waiting for being processed (queue length) and the average time that an order waits until be processed and delivered (waiting and response times) to the client.

\subsection{Numerical solution}

This section will be focused on numerical solution of system's performance. The numerical solution methods are well suited for evaluating systems that are too complex to be represented using the analytical methods. The stochastic Petri nets (SPNs) will be the numerical solution method covered in this section.

Since the first Petri nets proposition, different extensions were made. Nowadays, there are several types of Petri nets, each of them considering different aspects, like deterministic (Marsan \& Chiola, 1987) and stochastic times (Molloy, 1981), the differentiation between tokens (Jensen, 1997) and the hierarchical modeling (Jensen, 1991).

Stochastic Petri nets (SPNs) concepts (Marsan et al., 1995; Molloy, 1981) is a Petri net extension that associates probabilistic distributed times with transitions. Inhibition arcs, immediate transitions (Marsan et al., 1995), deterministic transitions (Marsan \& Chiola, 1987), general distribution functions (German, 1994), transitions' guards, marking-dependent features (transitions' weights and rates, arcs' multiplicity) (Ciardo et al., 1993) are some of the extensions proposed over the early SPN models. Such extensions grants to the SPNs the power of a Turing machine to describe the structural behaviour of the system (Ciardo et al., 1993). Some of the performance measures of SPNs are the average number of tokens in a place, the throughput of a transition, and average sojourn delay of a token in a place (Marsan et al., 1995).

These extensions resulted in several types of SPNs, like generalized stochastic Petri nets (GSPNs) (Balbo, 2001; Marsan et al., 1995), deterministic and stochastic Petri nets (DSPNs) (Marsan \& Chiola, 1987) , extended deterministic and stochastic Petri nets (eDSPNs) (German, 1994) and stochastic reward nets (SRNs) (Ciardo et al., 1993; Muppala et al., 1994). A SRN is a 10-tuple $N=\left(P, T, I, O, H, \Pi, G, M_{0}, W, \mathcal{R}\right)$, where (Ciardo et al., 1993):

- $P$ is the ordered set of places;

- $T$ is the ordered set of transitions, $P \cap T=\varnothing$; 
- $I \in\left(\mathbb{N}^{|P|} \rightarrow \mathbb{N}\right)^{|P| \times|T|}$ is the matrix of marking-dependent multiplicities of input arcs. If place $p_{j}$ is an input place of transition $t_{k}$, then $i_{j k} \geq 1$ else $i_{j k}=0$;

- $O \in\left(\mathbb{N}^{|P|} \rightarrow \mathbb{N}\right)^{|P| \times|T|}$ is the matrix of marking-dependent multiplicities of output arcs. If place $p_{j}$ is an output place of transition $t_{k}$, then $o_{j k} \geq 1$ else $o_{j k}=0$;

- $H \in\left(\mathbb{N}^{|P|} \rightarrow \mathbb{N}\right)^{|P| \times|T|}$ is the matrix of marking-dependent multiplicities of inhibition arcs. If place $p_{j}$ is an inhibition place of transition $t_{k}$, then $h_{j k} \geq 1$ else $h_{j k}=0$;

- $\Pi \in \mathbb{N}^{|T|}$ is the vector of transitions' priorities function. If transition $t_{k}$ is an immediate transition, then $\pi_{k} \geq 1$ else $\pi_{k}=0$;

- $G \in\left(\mathbb{N}^{|P|} \rightarrow\{\text { true, false }\}\right)^{|T|} \rightarrow\{$ true, false $\}$ is the vector of marking-dependent transitions' guards. If $t_{k}$ is enabled within $\mathbb{N}^{|P|}$, then $g_{k}=$ true else $g_{k}=$ false;

- $M_{0} \in \mathbb{N}^{|P|}$ is the vector of places' initial markings, where $\mu_{0_{j}} \geq 0, \forall p_{j} \in P$;

- $W \in\left(\mathbb{N}^{|P|} \rightarrow \mathbb{R}^{+}\right)^{|T|}$ is the vector of marking-dependent immediate transitions' weights and timed transitions' rates. For immediate transitions the $k-$ th element of $W$ is denoted by $w_{k}$, representing its weight. Regarding timed transitions, $\lambda_{k}$ is the $k$ - th element of $W$ and depicts its rate, which in turn must be greater than zero;

- $\mathcal{R}$ is a finite ordered set of rewards of $N$. Each element $\nabla_{i} \in \mathcal{R}$ is a triplet $(\rho, r, \psi)$ representing the $i$-th reward of the SRN, where: $\rho$ is a reward rate, $r$ is a reward impulse and $\psi$ is a reward based on the results of other rewards.

Elements $P, T, I, O, H, \Pi, G, M_{0}, W$ of the SRN describe a regular SPN. Considering that $\lambda$ is exponentially distributed for timed transitions, those elements describe a trivariate discrete-time stochastic process: $\left\{\left(t^{[n]}, \theta^{[n]}, \mu^{[n]}\right), n \in \mathbb{N}\right\}$, with $t^{[0]}=$ NULL, $\theta^{[0]}=0$, and $\mu^{[0]}=M_{0}$. For $n>0, t^{[n]} \in T$ is the $n$-th transition to fire, at marking $\mu^{[n-1]}$ leading to a new marking $\mu^{[n]}$ at time $\theta^{[n]}$. This stochastic process fully defines the SPN's underlying semi-Markov process (SMP) (Bolch et al., 2006; Ciardo et al., 1993; Muppala et al., 1994), where $\mu^{[n-1]}\left[t^{[n]}>\mu^{[n]}\right.$ represents the transition from marking $n-1$ to $n$ and $\theta^{[n]}-\theta^{[n-1]} \geq 0$ is the sojourn time at marking $\mu^{[n-1]}$. In this SMP, a sojourn times equal and greater than zero represent vanish and tangible markings, respectively (Bolch et al., 2006; Marsan et al., 1995). Furthermore, $\theta^{[n]}-\theta^{[0]}$ represents the total time spent from marking 0 until reaching marking $n$ (Ciardo et al., 1993).

The set with all possible values of $\mu[n]$ is the reachability set $(R S)$ of the SRN. Each element $\theta^{[n]}$ represents a discrete time at wich transition $t^{[n]}$ fires. The continuous-time Markov chain (CTMC) can thus be fully described by the depicted stochastic process, considering just the tangible markings of the Markov chain (Ciardo et al., 1993). Regarding to the depicted stochastic process, the marking at any time $x \geq 0$ is: $\mu(x)=\mu_{\max \left\{n: \theta^{[n]} \leq x\right\}}$. Thus, $\mu(x)$ is the marking $\mu^{[n]}$, where $\theta^{[n]}$ is at most equal to time $x$.

SRNs allows defining business-centric metrics beyond traditional SPNs' metrics, since they associate rewards with transitions firings and places markings at the net level. The underlying SPN's Markov chain is thus transformed into a Markov reward model (MRM). An MRM associates rewards with each state of the Markov chain (Tijms, 2003). In MRMs, Reward rates relate to the rate that the reward is accumulated while the system is in a state $s_{i}$. Reward impulses determines the amount of a reward that is instantaneously accumulated when the system goes from a state $s_{i}$ to a state $s_{j}$. MRM rewards are respectively represented by $\rho$ and $r$ components of each SRN's reward $\nabla_{i} \in \mathcal{R}$. 
Regarding $\mathcal{R}$, a reward rate function $\rho_{i}$ of a SRN depends on its markings, and is defined as $\rho: \mathbb{N}^{|P|} \rightarrow \mathbb{R}$, where $P$ is the set of places of the SRN. Thus, $\forall \mu \in R S, \rho_{i}(\mu)$ depicts the rate in which reward $i$ is accumulated while the system is in marking $\mu$, where $R S$ is the reachability set (Marsan et al., 1995).The reward impulse function $r_{i, t}$ regards to the amount of reward $i$ accumulated when a transition $t$ fires. Let $P$ and $T$ be the respective sets of places and transitions of a SRN, the reward impulse is a function $r_{i, t}: \mathbb{N}^{|P|} \rightarrow \mathbb{R}$. Thus, $\forall \mu \in R S$, $r_{i, t}(\mu)$ depicts the amount of reward $i$ that is accumulated in marking $\mu$ when transition $t$ fires. The stochastic process $\left\{\left(t^{[n]}, \theta^{[n]}, \mu^{[n]}\right), n \in \mathbb{N}\right\}$ among the rewards defined by $\rho$ and $r$ defines a new continuous stochastic process $\{Y(\theta), \theta \geq 0\}$ which relates to the SRN. The reward accumulated until a time $\theta$ is measured as described in Equation 5 (Ciardo et al., 1993).

$$
Y(\theta)=\int_{0}^{\theta} \rho(\mu(u)) d u+\sum_{j=1}^{\max \left\{n: \theta^{[n]} \leq \theta\right\}} r_{t^{[j]}}\left(\mu^{[j-1]}\right)
$$

The SRN's definitions presents each element of $\mathcal{R}$ as a triplet $(\rho, r, \psi)$. The third element of the triplet, $\psi$, is a function that computes a single value from the stochastic process $\{Y(\theta), \theta \geq 0\}$ described above. This function is defined as $\psi: R \rightarrow \mathbb{R}$, where $R$ is a set of real-valued stochastic processes. Considering the rewards triplets $(\rho, r, \psi)$, some of the measures that can be assessed with SRNs are presented in Table 1 (Ciardo et al., 1993).

\begin{tabular}{l|l|l}
\hline Description & Steady State & Up to $\theta$ \\
\hline Accumulated reward & $E\left[\lim _{\theta \rightarrow \infty} Y(\theta)\right]$ & $E[Y(\theta)]$ \\
\hline Time-averaged reward & $E\left[\lim _{\theta \rightarrow \infty} \frac{Y(\theta)}{\theta}\right]$ & $E\left[\frac{Y(\theta)}{\theta}\right]$ \\
\hline Instantaneous reward & - & $E\left[\lim _{\delta \rightarrow 0} \frac{Y(\theta+\delta)-Y(\theta)}{\delta}\right]$ \\
\hline $\begin{array}{l}\text { Number of transitions } \\
\text { firings }\end{array}$ & - & $E[Y(\theta)]$, where $\rho=0$ and $r=1$ \\
\hline $\begin{array}{l}\text { Prob. of acc. reward be } \\
\text { greater than } x\end{array}$ & $P\left[\lim _{\theta \rightarrow \infty} Y(\theta)>x\right]$ & $P[Y(\theta)>x]$ \\
\hline $\begin{array}{l}\text { Prob. of time-averaged } \\
\text { reward be greater than } x\end{array}$ & $P\left[\lim _{\theta \rightarrow \infty} \frac{Y(\theta)}{\theta}>x\right]$ & $P\left[\frac{Y(\theta)}{\theta}>x\right]$ \\
\hline Supremum reward rate & $\left.\begin{array}{l}\sup \\
n \geq 0\end{array} \rho(\mu): \operatorname{Pr}\left(\mu^{[n]}=\mu\right)>0\right\}$ & - \\
\hline
\end{tabular}

Table 1. Some SRNs measurements

Some elements (e.g. arc cardinality, transition rate) of a SRN are defined in function the current marking $\left(\mathbb{N}^{|P|}\right)$. SRNs uses only exponentially distributed functions for timed transitions. Nevertheless, it is still possible to represent other types of distributions. A well-known technique called phase approximation (Desrochers \& Al-Jaar, 1994) can be applied to represent poly-exponential distribution functions like Erlang, Hypo- and Hyper-Exponential distributions.

Since the timed transitions' rates are marking-dependent, they can be defined as single-, k-, or infinite-server, in the same sense as queueing networks. Let $N$ be a SRN, where $p_{j} \in P$ is the only input place of a transition $t_{k} \in T$, with rate 0.5 . The depicted server semantics are respectively represented by $\lambda_{k}=0.5, \lambda_{k}=0.5 \times \min \left(m_{j}, L\right)$ and $\lambda_{k}=0.5 \times m_{j}$, where $m_{j}$ is the marking of place $p_{j}$ in a given state and $L$ is the upper limit of the k-server semantics. In an SPN (and SRN), when two or more conflicting timed transitions are enabled at the same time, this conflict is solved through a race policy (Marsan et al., 1995). If immediate transitions are in conflict, the choice of which to fire takes into account the respective priority and weight 
levels. Suppose two immediate transitions $t 1$ and $t 2$ in conflict. If the priority of $t 1$ is greater than $t 2$, it will always fire first. If they have the same priority, the conflict is probabilistically solved considering their weights.

Usually, the Reachability Set and the Reachability Graph are simply referred as RS and RG, respectively. When the Petri net is not bounded, that is, there is a place that can have an infinite number of tokens, its RS and RG are also infinite. The RS and RG considering just the set of tangible markings are respectively known as Tangible Reachability Set (TRS) and Tangible Reachability Graph (TRG). This TRG can be converted to a continuous time Markov chain (CTMC), from which metrics could be calculated (Bolch et al., 2006). When the RG is too large, a subset of this graph can be explored using simulation.

\subsection{Simulation}

Chung (2004) defines the "simulation modeling and analysis is the process of creating and experimenting with a computerized mathematical model of a physical system". The simulation analysis allows modeling more details and variables of the real system. Metrics can thus be assessed based on a wider range of variables, when compared to analytical models. Since the analytical solution represents the real system using mathematical equations, it cannot take into account every variable that can directly or indirectly affect the real system. Otherwise, the equations could become to complex to be solved (Chung, 2004).

The simulation analysis does not provide exact results. Instead, it often adopts one or more stopping criteria. Once the evaluation reaches these criteria, the simulation stops and the metrics are considered to be found. The confidence interval, simulation length, simulated system time, amount of iterations for solving the problem, are examples of these criteria. Thus, if the stop criteria is not correctly defined, the results will not be reliable. The simulation analysis can also be used in conjunction or to replace analytical and numerical methods. For instance, it can support the evaluation of queueing networks and Petri nets, especially when the analytical or numerical solution is not possible due to the size of the model.

\section{An evaluation methodology}

This section presents an approach to assess environmental and cost indicators using SRN models. In order to achieve this assessment, reward functions should be associated to transitions and places of a SRN. These functions are calculated for each state of the SRN model returning a result that represents an environmental, cost or performance indicator.

The places and transitions of a Petri net are considered to be its respective passive and active elements. Input and output places of a transition often represent: preconditions and postconditions; input and output data; resources needed and resources released; input and output buffers. The amount of tokens in a place can thus represent the amount of resources located in such a place. Transitions often represent events, actions, a processor, etc.

Considering the presented semantics of places and transitions of a Petri net, it is possible to infer that the amount of stored products, could be represented by the number of tokens in a place that represents a store. In turn, the amount of goods produced per hour could be derived from a transition throughput that represents the producing rate.

The respective production and storage of goods might have other associated issues. For instance, producing goods may require energy and expel green house gases (GHG). As observed, it is possible to have several indicators associated with a single action. One might notice that these issues could be modeled as output places of a transition. But, it would 
increase the number of reachable states, hence demanding more computational resources for calculating measures, or even leading to a state-space explosion (Valmari, 1998).

Before the evaluation of a system, it is important to collect data to calculate the environmental indicators. After identifying the system's components (e.g.: machines, entities, processes) that are going to be represented in the model, the modeler should gather information about:

- Energy - The amount of resources consumed for energetic means. It is important to define the energy source (e.g. electricity, biomass, gasoline, diesel);

- Raw Materials - The amount of resources used to produce a good or realize an activity. Raw materials should be categorized by type (e.g. water, wood, hazardous, non-hazardous) and its origin (e.g. first use, reuse, recycled);

- Waste - The amount of waste generated by system's activities. This information should be structured by the type of the waste (e.g. wood, card, plastic) and by its destination (e.g. recycling, landfill, composting).

It is important to stress that a resource might be used as energy source, raw material or be a waste of an activity. For instance, a piece of wood can be used as energy source, as raw material in the production of a good, and some of it can also be wasted.

The proposed classification aims at providing means to separately measure GWP and exergy outputs of each activity/process, without being over-detailed avoiding a complex and inefficient evaluation process. Furthermore, a different value of GWP or exergy efficiency can be assigned to the same substance depending on its classification. For instance, a block of wood has a different GWP value when used as raw material of a good, disposed for recycling, or disposed in landfill. We chose this categorization based on the conversion factors usually adopted in LCA (Bösch et al., 2007; DEFRA - Department for Environment, Food and Rural Affairs, 2009; Goedkoop et al., 2000), in order to provide detailed description of the GWP of consumed/disposed resources.

Let $N$ be a SRN that models the evaluated system, $\mathcal{I}$ is its set with the classified energy, raw material, and waste items. For each element of $\mathcal{I}$ a reward $\nabla_{i} \in \mathcal{R}$ related to the consumption/disposal (in $\mathrm{kg}$ ) of the item should be defined. For convenience, the set with these basic rewards is denoted $\mathcal{R}_{\mathcal{I}}$, where $\mathcal{R}_{\mathcal{I}} \subseteq \mathcal{R}$.

An important remark considering the rewards definition is that they do not distinguish between places of the SRN. Instead, reward rates are based on the state of the SRN. But, sometimes it is wanted to have an insight of a specific process or a set of processes of the modeled system. In such cases, the rewards should be defined separately for each place and transition.

If such strategy is used, the total reward of a classified item should be derived from the sum of the rewards for each (or some) place and transition of the SRN. Let $N, P^{\prime} \subseteq P$ and $T^{\prime} \subseteq T$ be a SRN and its respective sets of places and transitions of $N$, for which it is intended to obtain the expected time-averaged reward of $\nabla_{i} \in\left(\mathcal{R}-\mathcal{R}_{\mathcal{I}}\right) . \nabla_{i}$ is measured as depicted in Equation 6.

$$
\nabla_{i}=\sum_{j=0}^{j=\left|\mathcal{R}^{\prime}\right|} \nabla_{j}
$$

where $\mathcal{R}_{\mathcal{I}}{ }^{\prime} \subseteq \mathcal{R}_{\mathcal{I}}$ is the set of rewards related to $\nabla_{i}$ that were defined for $p \in P^{\prime}$ and $t \in T^{\prime}$. The SRN presented in Figure 2 is used to exemplify the metrics definition. This SRN models a system where a hotel with 30 available rooms ( $p$ FreeRooms). The rooms are warmed by two furnaces, each capable of warming 15 rooms. The second furnace is turned on just when there 


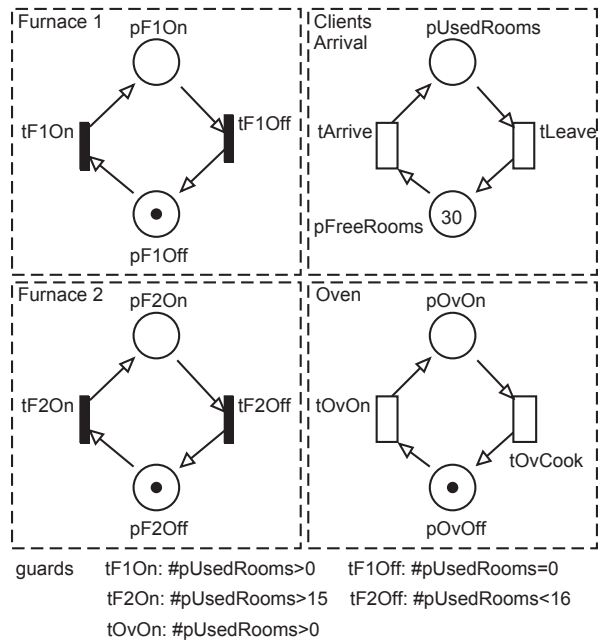

Fig. 2. Example of an SRN.

are more than 15 rooms occupied. These furnaces consumes natural gas at rate $x_{0}+n_{0} \lambda_{0}$ and $x_{1}+n_{1} \lambda_{1}$, respectively. Where $n_{0}$ and $n_{1}$ are factors that depends on the amount rooms occupied. Furthermore, transition tOvCook represents the use of an oven that consumes a fixed amount $z$ of the same gas each time it is used. Let $\sharp P$ represent the number of tokens in place $P$ and $\nabla_{i}=\left(\rho_{i}, r_{i}, \psi_{i}\right)$ represent the consumption of natural gas, this reward could be defined as follows:

$$
\begin{aligned}
\rho_{i}= & \sharp P F 1 O n\left(x_{0}+(\min \{\sharp p U \text { sedRooms }, 15\}) \lambda_{0}\right)+ \\
& \sharp P F 2 O n\left(x_{1}+(\max \{\sharp p U \text { sedRooms }-15,0\}) \lambda_{1}\right) \\
r_{i, t}= & z, t=t_{0} \wedge r_{i, t}=0, t \neq t_{0} ; \quad \psi_{i}=0
\end{aligned}
$$

It is important to remark that considering the defined natural gas reward, it is not possible to measure the amount consumed by a particular furnace. Instead the whole consumption is retrieved. If such information is required, these rewards should be defined separately, having their values totalized by another reward as depicted in Equation 6.

Assuming that the evaluated system produces physical goods (not virtual ones, as occurs with most informatics services) a mass balance analysis might be directly derived from the sum of all raw materials inputs and output goods (Equation 7).

$$
\nabla_{i}=\frac{\text { Qty good }_{\text {g }}}{\sum_{j=0}^{j=\left|\mathcal{R}^{\prime}\right|} \nabla_{j}}
$$

where $\mathcal{R}^{\prime} \subseteq \mathcal{R}$ is the set rewards that represents the input of raw materials (in $\mathrm{kg} /$ time) used in the production of the good and Qty good is the amount of goods produced per unit of time (in $\mathrm{kg} /$ time). Qty good could be obtained from the throughput of a SRN transition that represents the production of goods.

There are more three important rewards that should be defined in terms of each classified item. These rewards are: cost, global warming potential, and exergetic input/output. For each reward $\nabla_{i} \in \mathcal{R}_{\mathcal{I}}$, a cost reward $\nabla_{j} \in\left(\mathcal{R}-\mathcal{R}_{\mathcal{I}}\right)$ must be defined. The cost reward 
should assign a financial profit (positive signal) or expense (negative signal) related to the classified item. This reward is defined as

$$
\nabla_{j}=K+\beta \times \nabla_{i}
$$

where $K$ is a constant and $\beta$ is the unitary cost/profit for the classified item. The total financial cost/reward is simply depicted by the sum of the financial rewards.

For each reward $\nabla_{i} \in \mathcal{R}_{\mathcal{I}}$, a global warming potential reward $\nabla_{j} \in\left(\mathcal{R}-\mathcal{R}_{\mathcal{I}}\right)$ can also be defined as

$$
\nabla_{j}=g \times \nabla_{i}
$$

where $g$ is the GWP for each unit of the classified item. The total GWP is thus simply depicted by the sum of the GWP rewards.

For each reward $\nabla_{i} \in \mathcal{R}_{\mathcal{I}}$, that refers to energy consumption, an exergy input, output, and lost reward $\nabla_{j}, \nabla_{k}, \nabla_{l} \in\left(\mathcal{R}-\mathcal{R}_{\mathcal{I}}\right)$ can be respectively defined as

$$
\begin{aligned}
\nabla_{j} & =x_{c h} \times \nabla_{i} \\
\nabla_{k} & =\eta_{I I} \times \nabla_{j} \\
\nabla_{l} & =\nabla_{k}-\nabla_{j}
\end{aligned}
$$

where $\eta_{I I}$ and $x_{c h}$ are the weighted-average exergetic efficiency and chemical exergy of the used energy. The total exergy is thus simply depicted by the sum of the exergy rewards.

For each type of energy source consumed, the estimated exergetic efficiency of fuel $f$ regarding activity/location act represented by the SRN's transition/place should be informed $\left(\eta_{I I, a c t, f}\right)$. This efficiency factor in conjunction with the already known fuel's chemical exergy $\left(x_{c h, f}\right)$ allows calculating the exergy output in the activity $X_{\text {out,act }}$. Based on the exergy output (Equation 13), it is possible to compare the adoption of different types of energy sources. This comparison is carried out by considering that the exergy output of each activity must be the same regardless of the energy source. The amount (in $\mathrm{kg}$ ) of the energy source of the new energy source could be calculated using Equation 14. It is important to stress that changing the energy source would probably vary the exergetic efficiency $\eta_{I I}$ in the activity.

$$
\begin{aligned}
& X_{\text {out }, a c t_{i}, f_{1}}=\eta_{I I, a c t_{i}, f_{1}} \times x_{c h, f_{1}} \times Q_{\text {ty }_{a c t}, f_{1}}
\end{aligned}
$$

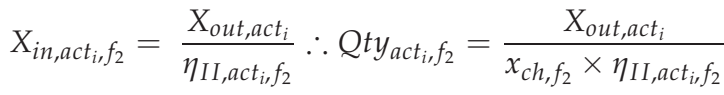

The cumulative exergy consumption could be directly derived from the sum of exergy inputs. Based on these inputs, the Life Cycle Exergy Analysis (LCEA) can be applied in the evaluated process, by accounting the exergy losses and the input exergy. The measured exergy outputs might be used in order to compare different energy sources considering Equation 14. Since each energy source might have a different GWP, this comparison provides insights about the environment impact resultant from the use of different energy sources.

\section{Modeling}

This section presents some SRN models that were conceived to represent facilities and processes of a supply chain and manufacturing systems. The manufacturing systems models were based on Desrochers \& Al-Jaar (1994). This library of components allows a bottom-up 
modeling. It also guarantees that the final model has some properties like boundedness, allowing either a steady state or transient evaluation (Alves et al., 2010).

Figure 3 presents the proposed components for modeling pull, push and reverse supply chains networks (Ballou, 2004; Fleischmann et al., 1997; Simchi-Levi et al., 2000) and manufacturing systems. The consumer component is not explicitly modeled in the push and reverse supply chains. It is represented by transition $t a$ of the flow model, which models the arrival of goods in the destination. Places named $p x D u a l$ are the dual places of places named $p x$. These places aim at guaranteeing that the final model is structurally bounded (Marsan et al., 1995), allowing a stationary analysis. The initial marking $M$ of these places should be high enough to guarantee that the marking of these places does not reach zero in any state, since these places cannot interfere in the system's behavior. Nevertheless, the higher these initial markings are, the larger the state space of the SRN will be. Therefore, the simulation can be required when evaluating the model. In order to tackle this problem, experiments can be conducted increasing these initial markings until the metrics remains statistically equals.

Table 2 lists typical business indicators that can be extracted from the proposed models. The entity column refers to the model from which the metric can be extracted, including factories $(\mathbf{F})$, intermediaries $(\mathbf{I})$, consumers $(\mathbf{C})$, flows $(\mathbf{F L})$, buffers $(\mathbf{B})$, processes $(\mathbf{P})$, and failures $(\mathbf{F L T})$.

\begin{tabular}{l|l|l}
\hline Entity & Performance Indice & Reward \\
\hline F or I & Expected inventory & $\sharp p s t$ \\
F or I & Prob. empty inventory & $\sharp p s t=0 ? 1: 0$ \\
F or I & Prob. full Inventory & $\sharp p s t D u a l=0 ? 1: 0$ \\
F or I & Available vehicles of kind $p t$ & $\sharp p t$ \\
F or I & Prob. more than $V$ vehicles of kind $p t$ available & $\sharp p t>V ? 1: 0$ \\
F or I & Prob. using all vehicles of kind $p t$ & $\sharp p t=0 ? 1: 0$ \\
C or I & Pending orders & $\sharp p a$ \\
C or I & Delivery throughput to customer & $\lambda(t a)$ \\
C or I & Customer order cycle time & $\sharp p a / \lambda(t a)$ \\
FL & Number of recent orders & $\sharp p o$ \\
FL & Number of backorders & $\sharp p s$ \\
FL & Prob. have more than $n$ Backorders & $\sharp p s>n ? 1: 0$ \\
FL & Customer service level & $1-(\sharp p s>0 ? 1: 0)$ \\
FL & $N^{o}$ of vehicles delivering to destination & $\sharp p t 1$ \\
FL & In-transit inventory & $c \times(\sharp p t 0+\sharp p t 1)$ \\
B & Buffer size & $\sharp p B$ \\
B & Prob. buffer full & $\sharp p B D u a l=0 ? 1: 0$ \\
P & $N^{o}$ of machines in use & $\sharp p P$ \\
P & $N^{o}$ of idle machines & $\sharp p M$ \\
P & $N^{o}$ of machines being released & $\sharp p R$ \\
P & Prob. more than $x$ machines in use & $\sharp p P>x ? 1: 0$ \\
FLT & $N^{o}$ of resources not in fail & $\sharp p O k$ \\
FLT & $N^{o}$ of resources waiting for repair & $\sharp p F a u l t$ \\
FLT & $N^{o}$ of resources being repaired & $\sharp p R e p a i r$ \\
FLT & Prob. of resources waiting for repair & $\sharp p F a u l t>0 ? 1: 0$ \\
FLT & Prob. of resources not in fail lower than $x$ & $\sharp p O k<x ? 1: 0$ \\
\hline & & \\
&
\end{tabular}

*Rewards are expressed based on the SPNP tool syntax (Hirel et al., 2000).

Table 2. Some metrics that can be extracted from models. 


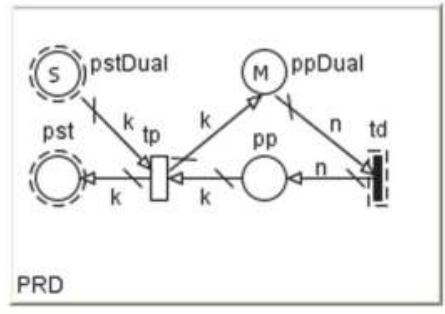

(a) Producer (pull).

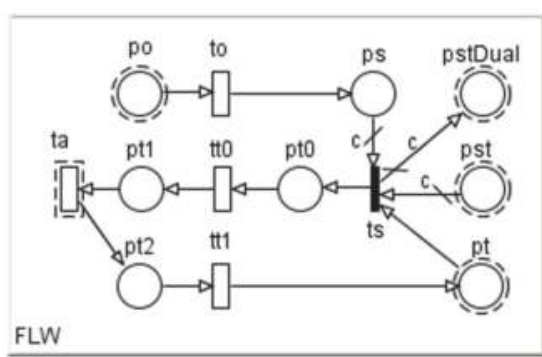

(d) Information/Goods Flow (pull).

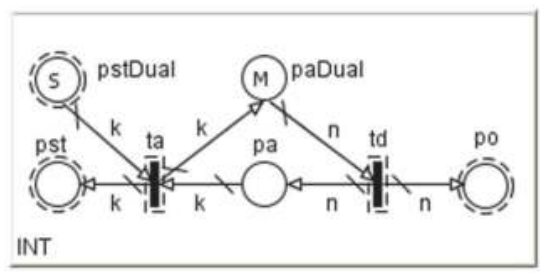

(b) Intermediary (pull).

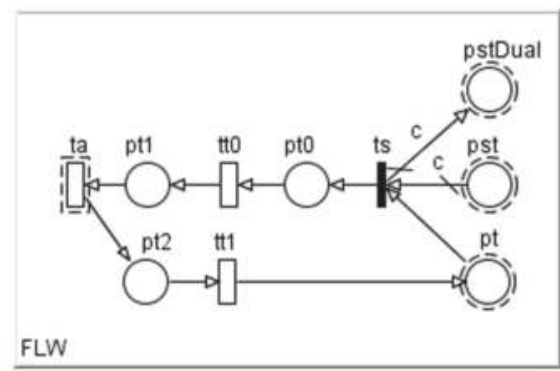

(e) Information/Goods Flow (push/reverse).

(f) $\mathrm{Pr}$

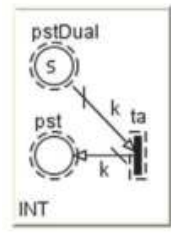

(g) Intermediary (push/reverse).

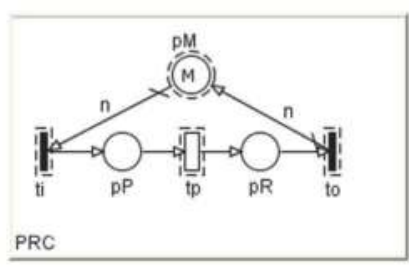

(h) Manufacturing Process.

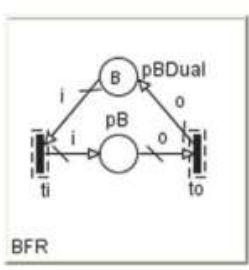

(i) Manufacturing Buffer.

Fig. 3. SRN models for entities and flows of a GSC. 


\subsection{Failures}

Failures occur quite often in supply chains. Delivering problems, broken products, vehicles or machines breaks are some of these failures that might partially or totally interfere with activities and processes. Depending on the failure and repair rate, the overal system's performance might also be affected. Figure 3(j) pictures the SRN that represents a failure.

The initial marking $R$ of $p O k^{F L T R_{i}}$ denotes the maximum amount of resources that might be used in an activity that is susceptible to failures. Transitions $t M T B F^{F L T R_{i}}$ and $t M T T R^{F L T R_{i}}$ respectively depict the mean time between failures and the mean time to repair. The rate of these transitions can be marking-dependent, allowing representing the server-semantics for the failures and repairing activities.

The failure rate can depend on the marking of $p O k^{F L T R_{i}}$ which represents the amount of resources being used. The repair rate can represent a limitation on the maintenance team. For instance, if the system has limited amount of resources $n$ in the maintenance team. Thus, if there are more than $n$ machines broken, just $n$ of these machines will be fixed in turn. Thus, the repair rate could be defined as $\lambda \times \min \left(n, p \operatorname{Repair} F L T R_{i}\right)$, where $\lambda$ is the time required to fix a single machine. If a machine could be fixed by more than one resource at the same time, the repair rate could be even lower, being defined as $\lambda \times n$.

This model can also represent failures occurring in more than one activity. The rate of transition $t M T B F^{F L T R_{i}}$ represents the failure rate when a set of activities are being executed, or the absolute time between failures. In the first case, it is necessary to assign a guard $\left[t_{k}>, \forall t_{k} \in T^{\prime}\right.$ to transition $t M T B F^{F L T R_{i}}$, where $T^{\prime}$ is the set of transitions that represents activities susceptive to the modeled failure.

The guards and rates of such transitions must also depend on the failure model. If a transition $t_{k} \in T^{\prime}$ must have at least $n$ resources working to be fired, it must have a guard $\sharp p O k^{F L T R_{i}} \geq$ $n$, where $n$ is an integer. In the case of $n=R$ if a single resource is in the fail state, the activity represented by $t_{k}$ halts. Alternatively, the FLTR can be reduced by removing transition tRepair $F^{2} R_{i}$ and place $p R e p a i r F L T R_{i}$. It can be done when it is not necessary to represent the limited maintenance resources.

\subsection{Replenishment policies}

Replenishment policies are considered for changing the way that intermediaries order goods and manufacturers produce them. Make-to-order (MTO) policy means that finished goods are manufactured only when an order from a customer is received. Under make-to-stock (MTS) policies, finished goods are manufactured and stored. Customers orders are thus supplied from storage. The proposed models supports the following replenishment policies(Simchi-Levi et al., 2000): $(\mathbf{r}, \mathbf{Q}),(\mathbf{r}, \mathbf{s}, \mathbf{Q}),(\mathbf{r}, \mathbf{S}),(\mathbf{r}, \mathbf{s}, \mathbf{S})$ and $(\mathbf{s}, \mathbf{S})$, where $\mathbf{r}$ is the review interval, $\mathbf{Q}$ is the amount of goods per order, $\mathbf{s}$ and $\mathbf{S}$ are the minimal and target inventory level, respectively.

For the sake of simplicity, the models in Figure 3 use the $(r, Q)$ replenishment policy. The replenishment policy of factories and intermediaries can be changed considering the models pictured in Figure 4.

The periodical ordering component models either the $(r, Q)$ and $(r, S)$ policies. The $(r, Q)$ policy is modeled assigning an integer value $Q$ to the arc weight $n$ and $1 / r$ to the rate of transition $t d$. The $(r, S)$ policy is modeled assigning the same rate to transition $t d$ and a marking dependent function $S-I$ to the arc weight $n$, where $I$ is the current inventory position $(\mu(p a)+\mu(p s t))$. 


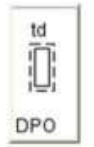

(a) Periodic Ordering.

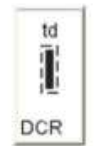

(b) Continuous Review.

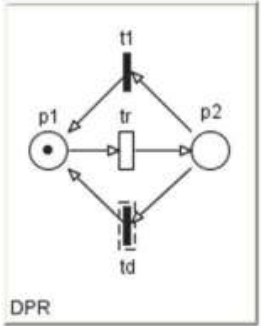

(c) Periodic Review.

Fig. 4. Replenishment policies models.

The continuous review component models $(s, Q)$ and $(s, S)$ policies. The $(s, Q)$ policy is modeled by setting an integer value $Q$ to the arc weight $n$ and the guard $I<s$ to the transition $t d$, where $I$ is the current inventory position. The $(s, S)$ policy should be modeled in a similar way to $(s, Q)$ policy, but assigning a marking dependent function $S-I$ to the arc weight $n$. This model can also be considered for modeling a MTO policy. This policy should be modeled by assigning the arc weight $n=B a c k l o g$ and a guard Backlog $>0$ to transition $t d$, where Backlog = Backorders - Stored Inventory - Inventory on Order and the Backorders depicts the sum of the backorders of all the facility's customers. For factories, the Inventory on Order depicts its work-in-process (WIP).

The periodic review component models either the $(r, s, Q)$ and $(r, s, S)$ policies. These policies are modeled by setting the guard $I<s$ to the transition $t d$ and $1 / r$ to the rate of transition tr. A marking dependent function $S-I$ must be assigned to arc weight $n$ when considering the $(r, s, Q)$ policy, whilst an integer value $Q$ must be set to arc weight $n$, when considering the $(r, s, S)$ policy. The priority of transition $t d$ must be greater than that one of transition $t 1$. Thus, whenever a conflict occurs between these transitions, $t d$ will always be fired, triggering the replenishment order.

It is also possible to adopt a hybrid policy by composing different replenishment models. For instance, a factory can adopt a MTS policy for a set of clients and a MTO policy for other clients. This is especially useful for facilities that faces demands with high variation (Soman et al., 2002). Multiple MTS policies could also be used together with the aim of modeling seasonality on demand.

\subsection{Supply chain network}

Based on the library of components presented in this section, modelers can design and experiment different configurations for a supply chain (SC). Figure 5 shows the models for two different SCs. The elements' names were intentionally suppressed for a better readability. The model showed in Figure 5(a) represents a pull SC, in which a factory (Factory_0) sends its products to two different customers (Customer_0 and Customer_1). This factory uses an $(r, s, S)$ policy, with the minimal and target inventory levels of 50 and 100, respectively. The minimal replenishment policy is depicted by transitions' guards mark ("pst_PRD_0" $)<50$, whilst the target inventory is depicted by arcs' weights 100 - mark("pst_PRD_0").

The transportation of goods is done using 3 vehicles of the same type. This amount is represented by the initial marking of a place represented inside the Flow_0 component. These 
resources are shared between the flows Flow_0 and Flow_1. The customers are respectively supplied with 10 and 15 units of goods per order, as showed by the arcs with such weights.

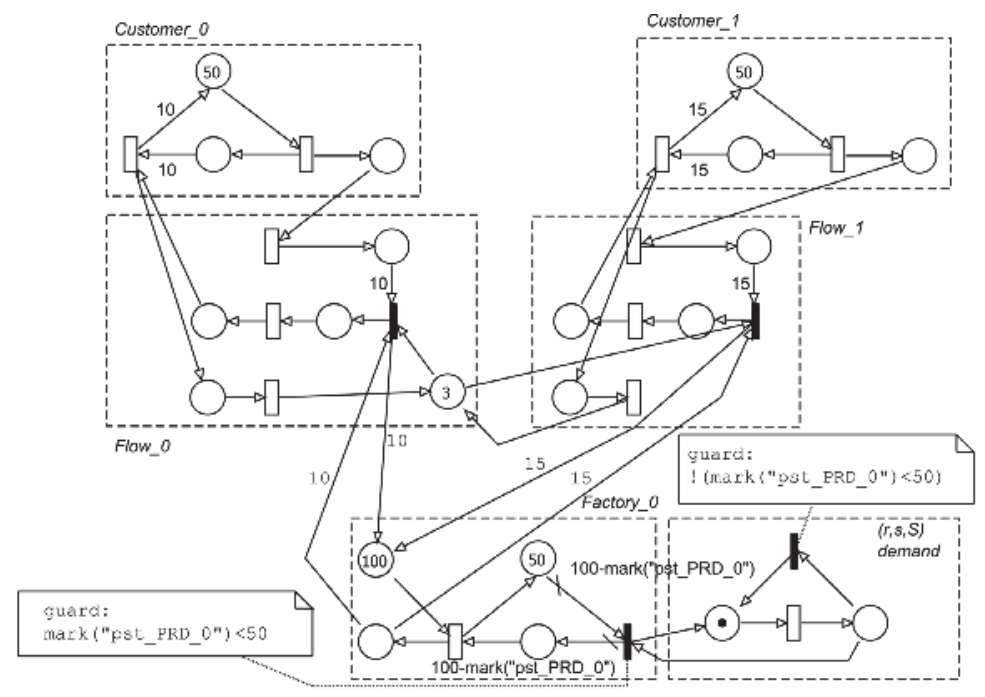

(a) Pull.

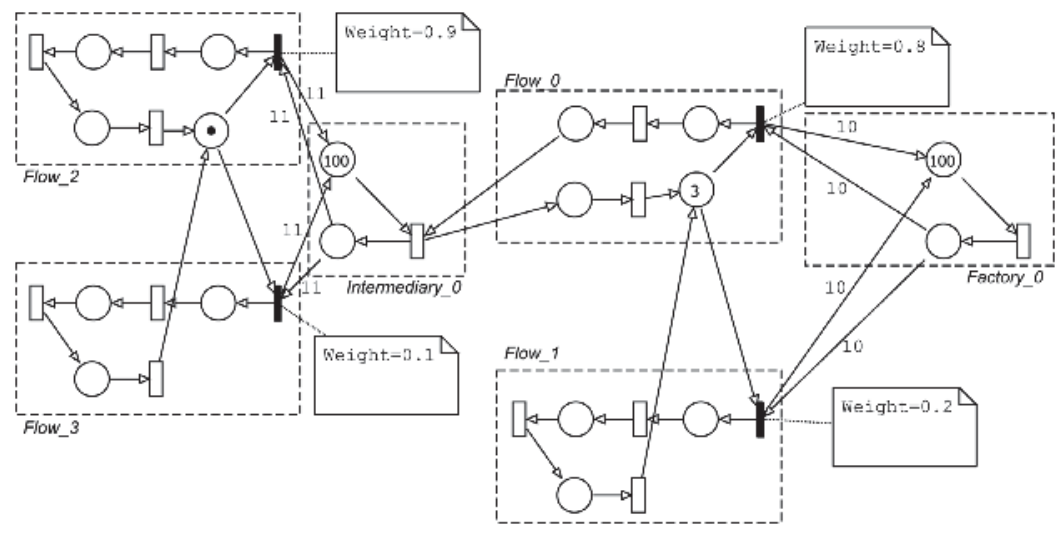

(b) Push.

Fig. 5. SRN models for supply chains.

The model pictured in Figure 5(b) represents a push SC, in wich a factory (Factory_0) sends its products both to a customer (Flow_1) and to an intermediary (Intermediary_0). Besides, the goods are send to the intermediary through the a flow represented by Flow_0. The intermediary serves two consumers (Flow_2 and Flow_3). As depicted previously in this section, the final customers are represented by the flow components in models of push supply chains. The factory and the intermediary serve their clients using 3 and 1 vehicle, respectively. Furthermore, they respectively send 10 and 11 goods to their clients per delivery. 
When using the models for pull supply chains, the immediate transitions weights represent the probability of sending goods for each client of the producer. In the example, $80 \%$ of the factory's deliveries are addressed to the intermediary and $20 \%$ are addressed to its consumer.

\section{Case study}

This section presents a case study conducted in a Brazilian meat processing industry. This study considers a production line composed of different machines and sub-processes. These elements were grouped in stages of the production line. We thus mapped three main stages which will be called Stage 1, Stage 2 and Stage 3. These stages consumes 63.68, 102.94, and 22.96 $\mathrm{kWh} /$ ton of electricity, respectively. Furthermore, the second production stage also consumes $26.76 \mathrm{~m}^{3} /$ ton of natural gas. This case study focuses on energy consumption. Beyond environment issues, we also model the failures at each stage. We address this issue to assess the impact of failures in the system performance. This impact might provide information for decisions on the maintenance of the production line's machines.
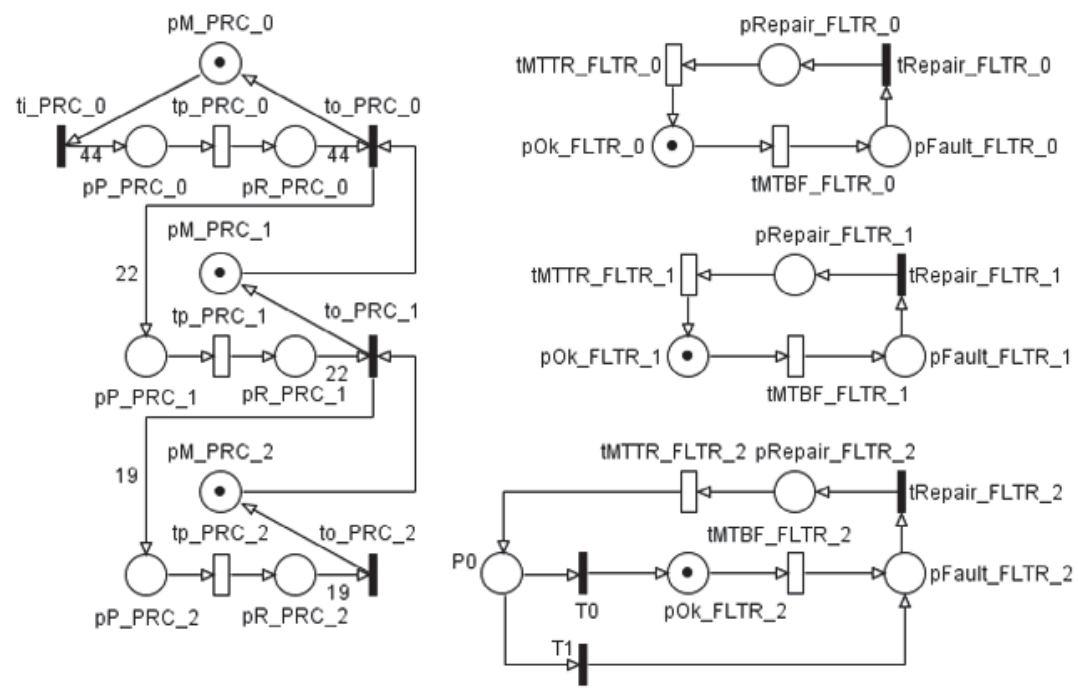

Fig. 6. Stochastic reward net for the production line.

Figure 6 shows the SRN model for the production line. As observed in such a model, the failures were also represented. It is thus possible to compare their effects over performance and environmental metrics. Since for this kind of problem the occurrence of failures may affect not only the availability but also the system performance, they could not be modeled in separate. Considering the data collected, the phase approximation was applied in this model. The rates of the three production stages were approximated to an Erlang distribution with 44, 22, and 19 phases, respectively. The failures occur with a hyper-exponential behavior in the third stage and with an exponential behavior in the other stages.

Table 3 provides a summary of the exergetic values adopted for following calculations (Kotas, 1985). Such efficiencies are used in the exergy/GWP comparison. The natural gas and fuel oil efficiencies considered for powering machines represent the efficiency for converting the energy source into electricity, that in turn could be directly used by machines. 


\begin{tabular}{l|c|c|c}
\hline Source & Use & Efficiency $\left(\eta_{I I}\right)$ & $x_{c h, f}(\mathbf{k J} / \mathbf{k g})$ \\
\hline Electricity & Power & 0.92 & 3600 \\
Electricity & Cooking & 0.115 & 3600 \\
Natural Gas & Power & 0.2931 & 51702 \\
Natural Gas & Cooking & 0.233 & 51702 \\
Fuel Oil & Power & 0.3207 & 47101 \\
Fuel Oil & Cooking & 0.233 & 47101 \\
\hline
\end{tabular}

Table 3. Exergy efficiency per source and use.

\begin{tabular}{|c|c|c|c|c|}
\hline Metric & Stage & Expression & Scenario 1 & Scenario 2 \\
\hline rate1 (un./hour) & 1 & return rate("tp_PRC_0")/44.0; & 4.13629 & 3.81797 \\
\hline n./hour) & 2 & return rate("tp_PRC_1")/22.0; & 4.13629 & 3.81739 \\
\hline rate3 (un./hour) & 3 & return rate("tp_PRC_2")/19.0; & 4.13629 & 3.81551 \\
\hline atilization1 (\%) & 1 & return mark("pP_PRC_0")>0?1.0:0.0; & 0.94150 & 0.87566 \\
\hline utilization2 (\%) & 2 & return mark("pP_PRC_1")>0?1.0:0.0; & 0.79796 & 0.77152 \\
\hline utilization3 (\%) & 3 & return mark("pP_PRC_2")>0?1.0:0.0; & 0.83307 & 0.80724 \\
\hline 1 (un./hour) & 1 & return mark("pRepair_FLTR_0"); & & 580 \\
\hline repairing2 (un./hour) & 2 & return mark("pRepair_FLTR_1"); & - & 0.03292 \\
\hline repairing3 (un./hour) & 3 & return mark("pRepair_FLTR_2"); & - & 0.04039 \\
\hline waiting_repair1 (un./hour) & 1 & return mark("pFault_FLTR_0"); & - & 0.00000 \\
\hline waiting_repair2 (un./hour) & 2 & return mark("pFault_FLTR_1"); & - & 0.00000 \\
\hline waiting_repair3 (un./hour) & 3 & return mark("pFault_FLTR_2"); & - & 0.00000 \\
\hline el1 (k) & 1 & return $\left(63.6812^{*}\right.$ rate 1()$)$; & 263.40376 & 243.13300 \\
\hline el2 $(\mathrm{kW}$ & 2 & $02.9402^{*}$ rate 2()$)$; & 425.79028 & 392.96251 \\
\hline el3 (kWh/hour) & 3 & return $(22.9600 *$ rate3()); & 94.96916 & 87.60421 \\
\hline gas2 $\left(m^{3} /\right.$ hour $)$ & 2 & return $\left(26.7559^{*}\right.$ rate2()); & 110.67010 & 102.13761 \\
\hline X_in_el1 (MJ/hour) & 1 & return $\left(3.6^{*} \mathrm{el} 1()\right)$; & 948.25354 & 875.27880 \\
\hline X_in_el2 (MJ/hour) & 2 & return $\left(3.6^{*} \mathrm{el} 2()\right)$; & 1532.84500 & 1414.66503 \\
\hline X_in_el3 (MJ/hour) & 3 & return $\left(3.6^{*} \mathrm{el} 3()\right)$; & 341.88899 & 315.37515 \\
\hline X_in_gas2 (MJ/hour) & 2 & return $\left(51.702^{*} 0.714^{*}\right.$ gas 2() & 4085.41194 & 3770.43302 \\
\hline X_out_power (MJ/hour) & system & return $0.92^{*}(\mathrm{X}$ in_el1()+X_in_el2()+X_in_el3()); & 2597.14854 & 2396.89347 \\
\hline X_out_cooking (MJ/hour) & system & return $\left(0.233^{*} \mathrm{X}_{\text {_in_gas }}(2)\right)$; & 951.90098 & 878.51089 \\
\hline
\end{tabular}

Table 4. Reward functions and results. 
Table 4 presents the reward functions adopting the SPNP tool syntax (Hirel et al., 2000). We used this tool to compute these rewards in the steady-state. Table 4 also depicts the results of three scenarios that were carried out. The first scenario disregards system's failures. The second one includes failures but considers an unlimited maintenance team. The third scenario considers that there is only one resource available in this team.

The results presented in Table 4 shows that the inclusion of failures reduces in almost $8 \%$ the production rate (from 4.13629 to 3.81551 ). This rate represents the amount tons of goods are produced per hour. Besides, the lower utilization of the second stage sugests that it is a bottleneck in the system. So, investments in this stage should be prioritized.

The third scenario, which considers a limited maintenance team, presents results that are quite similar to those provided by the second scenario, which disregards this limitation. The difference in the results are due to the errors inherent from the model simulation. Thus, considering the current failures and maintenance rates, a single maintenance team could meet the needs of this production line. But changes in these variables, might require the evaluation of new scenarios to check if this assumption remains true.

The following analysis are based on the second scenario that represents the actual situation of the production line. Assuming the current operation of the industry, it is possible to infer that the consumption of electricity and natural gas assigns a GWP of $72 \mathrm{~kg} \mathrm{CO} \mathrm{CO}_{2} \mathrm{e} / \mathrm{ton}$ of goods, considering $0.0959 \mathrm{~kg} \mathrm{CO} 2 e$ per $\mathrm{kWh}$ of electricity and $2.01330 \mathrm{~kg} \mathrm{CO} \mathrm{CO}_{2} e$ per $\mathrm{kg}$ of natural gas (DEFRA - Department for Environment, Food and Rural Affairs, 2009). The electricity conversion factor is specific for Brazil, the world's average is $0.3827 \mathrm{~kg} \mathrm{CO}_{2} e$ per $\mathrm{kWh}$. If this conversion factor was adopted, the resulting GWP should be of $126.5 \mathrm{~kg} \mathrm{CO}_{2} \mathrm{e} / \mathrm{ton}$ of goods.

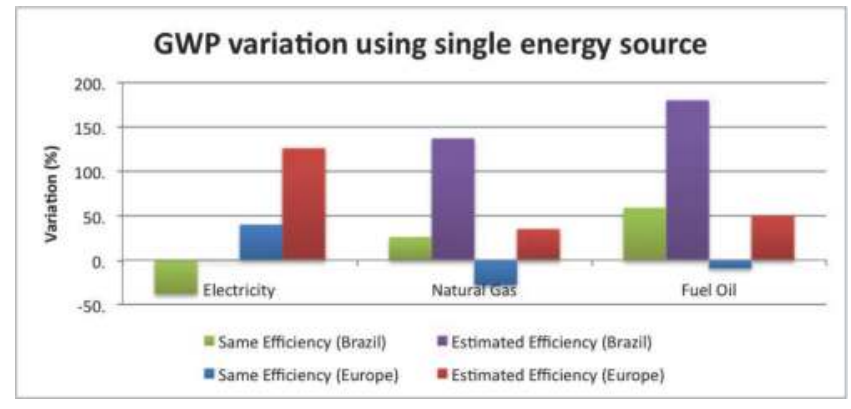

Fig. 7. Impact of energy source over GWP.

We calculated the amount of exergy input necessary to generate the same exergy output (see Table 4) with a single energy source. Based on that exergy input, we calculate the GWP and compared it to the actual operation of the production line. Figure 7 presents that comparison result. The graphs labeled as "Same Efficiency" assume a hypothetical situation where the current efficiency $\eta_{I I, a, f}$ is preserved. The "Estimated Efficiency" graphs depict the variation in a real scenario where the exergetic efficiency changes according to the energy source.

It is possible to observe that considering an hypothetical situation where the exergy efficiency is preserved, the use of natural gas as the single energy source decreases the GWP in european countries, whilst in Brazil, this value increases. It occurs due to the fact that in Brazil, the GWP factor of the energy is very low when compared to other countries, due to the extensive use of hydroelectric energy. 
Regarding the real efficiencies, despite of the fact that the exergetic efficiency of the electricity for cooking processes is lower than that one of the natural gas, the GWP variation remains almost constant when the electricity is used as the only energy source in Brazil. Furthermore, although the fuel oils have a high chemical exergy, their high GWP concentration make them the worst alternative from the environmental point of view. Analysis of costs might justify their usage in some points of the production line in detriment to environment impacts.

\section{Final remarks}

This chapter presented a framework based on the stochastic modeling of supply chains for evaluating business and sustainability metrics. Such a framework uses the stochastic reward nets (SRNs) as modeling technique. Furthermore, the GWP and exergy measurements form the basis for the environment performance evaluation (EPE) of this framework. Although, the life cycle assessment (LCA) is a very good tool for measuring static sustainability impacts of a product, it is not well suited for predicting the impacts of a system reengineering. The presented framework reveals itself very useful in such cases.

The case study in the end of the chapter highlights the importance of considering not only the energy source, but also the localities, that means, the effects of the system location (e.g. country, city, etc) over evaluated metrics. Especially for the electricity, the GWP factor might vary substantially according to the country that is using such issue. Together with business metrics like costs, resources utilization and customers backorders, the environment metrics provides information for decision makers.

\section{References}

Alves, G., Maciel, P., Lima, R. \& Zimmermann, A. (2010). Automatic Modeling for Performance Evaluation of Inventory and Outbound Distribution, Systems, Man and Cybernetics, Part A: Systems and Humans, IEEE Transactions on 40(5): 1025-1044.

Apaiah, R. K., Linnemann, A. R. \& van der Kooi, H. J. (2006). Exergy analysis: A tool to study the sustainability of food supply chains, Food Research International 39(1): 1-11.

Ayres, R. U., Ayres, L. W. \& Martinás, K. (1998). Exergy, Waste Accounting, and Life-Cycle Analysis, Energy 23(5): 355-363.

Balbo, G. (2001). Introduction to Stochastic Petri Nets, LNCS 2090 pp. 84-155.

Ballou, R. H. (2004). Business Logistics/Supply Chain Management, 5 edn, Pearson Education.

Beamon, B. M. (1999). Designing the green supply chain, Logistics Information Management 12(4): 332-342.

Bolch, G., Greiner, S., de Meer, H. \& Trivedi, K. (2006). Queueing Networks and Markov Chains: Modeling and Performance Evaluation with Computer Science Applications , 2 edn, John Wiley \& Sons, New York, NY, USA.

Bösch, M. E., Hellweg, S., Huijbregts, M. A. J. \& Frischknecht, R. (2007). Applying Cumulative Exergy Demand (CExD) Indicators to the ecoinvent Database, The International Journal of Life Cycle Assessment 12(3): 181-190.

Cascio, J. (1999). The Iso 14000 Handbook, ASQ Quality Press.

Cash, R. \& Wilkerson, T. (2003). GreenSCOR: Developing a Green Supply Chain Analytical Tool. LMI - Logistics Management Institute.

Chen, H., Amodeo, L., Chu, F. \& Labadi, K. (2005). Modeling and performance evaluation of supply chains using batch deterministic and stochastic petri nets, IEEE Trans. on Automation Science and Engineering 2(2): 132-144. 
Chung, C. (2004). Simulation Modeling Handbook: A Practical Approach, CRC Press.

Ciardo, G., Blakemore, A., Chimento, P., Muppala, J. \& Trivedi, K. (1993). Automated generation and analysis of markov reward models using stochastic reward nets, IMA Volumes in Mathematics and its Applications 48: 145-145.

Cohen, M. \& Lee, H. (1988). Strategic analysis of integrated production-distribution systems: models and methods, Operations Research 36(2): 216-228.

Cornelissen, R. L. \& Hirs, G. G. (2002). The value of the exergetic life cycle assessment besides the lca, Energy Conversion and Management 43: 1417-1424.

DEFRA - Department for Environment, Food and Rural Affairs (2009). 2009 Guidelines to Defra / DECC's GHG Conversion Factors for Company Reporting.

Desrochers, A. A. \& Al-Jaar, R. Y. (1994). Applications of Petri Nets in Manufacturing Systems: Modeling, Control, and Performance Analysis, Institute of Electrical \& Electronics Enginee.

Dotoli, M. \& Fanti, M. P. (2005). A generalized stochastic petri net model for management of distributed manufacturing systems, CDC-ECC05, 44th IEEE Conference on Decision and Control and European Control Conference, pp. 2125-2130.

Fleischmann, M., Bloemhof-Ruwaard, J. M., Dekker, R., van der Laan, E., van Nunen, J. A. E. E. \& van Wassenhove, L. N. (1997). Quantitative models for reverse logistics: A review, European Journal of Operational Research 103: 1-17.

Fleischmann, M., Kuik, R. \& Dekker, R. (2002). Controlling inventories with stochastic item returns: A basic model, European Journal of Operational Research 138(1): 63-75.

Frischknecht, R., Jungbluth, N., Althaus, H., Doka, G., Dones, R., Heck, T., Hellweg, S., Hischier, R., Nemecek, T., Rebitzer, G. \& Spielmann, M. (2005). The ecoinvent Database: Overview and Methodological Framework, The International Journal of Life Cycle Assessment 10(1): 3-9.

GaBi Software - product sustainability (2010). Website.

URL: http://www.gabi-software.com

German, R. (1994). Analysis of stochastic Petri nets with non-exponentially distributed firing times, $\mathrm{PhD}$ thesis, Technische Universität Berlin.

Goedkoop, M., Spriensma, R. et al. (2000). The Eco-indicator 99, PRé Consultants.

Gong, M. \& Wall, G. (2001). On exergy and sustainable development-part 2: Indicators and methods, Exergy, An International Journal 1(4): 217-233.

Gross, D. (2009). Fundamentals of Queueing Theory, 4 edn, John Wiley \& Sons Inc.

Guide, Jr., V. D. R., Souza, G. C. \& van der Laan, E. (2005). Performance of static priority rules for shared facilities in a remanufacturing shop with disassembly and reassembly, European Journal of Operational Research 164(2): 341-353.

Haas, P. J. (2002). Stochastic petri nets: Modelling, stability, simulation, Springer.

Heijungs, R., Guinée, J., Huppes, G., Lankreijer, R., Udo de Haes, H., Wegener Sleeswijk, A., Ansems, A., Eggels, P., Duin, R. \& Goede, H. (1992). Environmental life cycle assessment of products, Centre of Environmental Science. University of Leiden.

Hirel, C., Tuffin, B. \& Trivedi, K. (2000). SPNP: Stochastic Petri Nets. Version 6.0, Computer Performance Evaluation. Modelling Techniques and Tools, Vol. 1786, Springer Verlag, pp. 354-pp.

IPCC (2001). Climate Change 2001: The Scientific Basis, Cambridge University Press.

ISO (2006). ISO 14040:2006 - Environmental management - Life cycle assessment - Principles and framework, Technical report, ISO - International Organization for Standards. 
Jensen, K. (1991). Coloured Petri Nets: A High Level Language for System Design and Analysis, LNCS; Advances in Petri Nets 1990 483: 342-416. NewsletterInfo: 39.

Jensen, K. (1997). Coloured Petri Nets: Basic Concepts, Analysis Methods and Practical Use, Vol. 1, Springer-Verlag.

Kotas, T. J. (1985). The Exergy Method of Thermal Plant Analysis, Butterworths.

Labadi, K., Chen, H. \& Amodeo, L. (2007). Modeling and performance evaluation of inventory systems using batch deterministic and stochastic petri nets, Systems, Man, and Cybernetics, Part C: Applications and Reviews, IEEE Transactions on 37(6): 1287-1302.

Lee, H. L., Padmanabhan, V. \& Whang, S. (1997). The Bullwhip Effect in Supply Chain, Sloan Management Review 38(3).

Lettieri, D. J., Hannemann, C. R., Carey, V. P. \& Shah, A. J. (2009). Lifetime exergy consumption as a sustainability metric for information technologies, Sustainable Systems and Technology, 2009. ISSST '09. IEEE International Symposium on, pp. 1-6.

Louwers, D., Kip, B. J., Peters, E., Souren, F. \& Flapper, S. D. P. (1999). A facility location allocation model for reusing carpet materials, Comput. Ind. Eng. 36(4): 855-869.

Makajic-Nikolic, D., Panic, B. \& Vujosevic, M. (2004). Bullwhip Effect and Supply Chain Modelling and Analysis using CPN Tools, 5th Workshop and Tutorial on Practical Use of Coloured Petri Nets and the CPN Tools.

Marsan, M. A., Balbo, G., Conte, G., Donatelli, S. \& Franceschinis, G. (1995). Modelling with Generalized Stochastic Petri Nets, John Wiley \& Sons.

Marsan, M. A. \& Chiola, G. (1987). On petri nets with deterministic and exponentially distributed firing times, Advances in Petri Nets 1987, covers the 7th European Workshop on Applications and Theory of Petri Nets, Springer-Verlag, London, UK, pp. 132-145.

Molloy, M. K. (1981). On the Integration of Delay and Throughput Measures in Distributed Processing Models, PhD thesis, UCLA.

Moore, K. E., Gungor, A. \& Gupta, S. M. (1998). A Petri net approach to disassembly process planning, Computers $\mathcal{E}$ Industrial Engineering 35(1-2): 165-168.

Muppala, J., Ciardo, G. \& Trivedi, K. (1994). Stochastic reward nets for reliability prediction, Communications in reliability, maintainability and serviceability 1(2): 9-20.

Murata, T. (1989). Petri nets: Properties, analysis and applications, Proceedings of the IEEE 77(4): 541-580.

Narahari, Y. \& Biswas, S. (2007). Performance Measures and Performance Models for Supply Chain Decision Making, University Book Series, ICFAI (Institute of Chartered Financial Analysts of India), chapter 7.

Norris, J. (1998). Markov Chains, Cambridge University Press.

Oliveira Filho, D. (1995). Electric Energy System Planning and the Second Principle of Thermodynamics, PhD thesis, McGill University, Montreal, Canada.

Petri, C. A. (1962). Kommunikation mit Automaten, PhD thesis, Bonn: Institut für Instrumentelle Mathematik, Schriften des IIM Nr. 2.

Raghavan, N. R. S. \& Roy, D. (2005). A Stochastic Petri Net Approach for Inventory Rationing in Multi-Echelon Supply Chains, Journal of Heuristics 11(5-6): 421-446.

Ramchandani, C. (1994). Analysis of Asynchronous Concurrent Systems by Timed Petri Nets, PhD thesis, MIT, Cambridge, MA.

Rosen, M. \& Dincer, I. (2003). Exergy-cost-energy-mass analysis of thermal systems and processes, Energy Conversion and Management 44(10): 1633-1651.

Sabri, E. \& Beamon, B. (2000). A multi-objective approach to simultaneous strategic and operational planning in supply chain design, Omega 28(5): 581-598. 
Sato, N. (2004). Chemical Energy and Exergy: An Introduction to Chemical Thermodynamics for Engineers, Elsevier Science Publishers.

Sciubba, E. (2003). Extended exergy accounting applied to energy recovery from waste: The concept of total recycling, Energy 28(13): 1315-1334.

Silva, M. \& Maciel, P. (2005). Modelling and analysis of inventory policy: an approach based on petri nets, International IEEE Conference on Systems, Man and Cybernetics, Hawaii.

SimaPRO LCA Software (2010). Website.

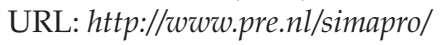

Simchi-Levi, D., Bramel, J. \& Chen, X. (2005). The logic of logistics: theory, algorithms, and applications for logistics and supply chain management, Springer Verlag.

Simchi-Levi, D., Kaminsky, P. \& Simchi-Levi, E. (2000). Designing and managing the supply chain: concepts, strategies and case studies, McGraw-Hill.

Soman, C. A., van Donk, D. P. \& Gaalman, G. (2002). Combined make-to-order and make-to-stock in a food production system, Technical report, University of Groningen, Research Institute SOM (Systems, Organisations and Management).

Srivastava, S. K. (2007). Green Supply-Chain Management: A State-of-the-Art Literature Review, International Journal of Management Reviews 9(1): 53 - 80.

Szargut, J. \& Morris, D. R. (1985). Cumulative exergy consumption and cumulative degree of perfection of chemical processes, Int. Journal of Energy Research 11(2): 245-261.

Szargut, J., Morris, D. R. \& Steward, F. R. (1988). Exergy Analysis of Thermal, Chemical, and Metallurgical Processes, Hemisphere Publishing Corporation.

Szargut, J., Valero, A., Stanek, W. \& Valero, A. (2005). Towards an international reference environment of chemical exergy, 18th International Conference on Efficiency, Cost, Optimization, Simulation and Environmental Impact of Energy Systems (ECOS), pp. 409-417.

Tijms, H. (2003). A first course in stochastic models, John Wiley \& Sons Inc.

Valmari, A. (1998). The state explosion problem., LNCS: Lectures on Petri Nets I: Basic Models 1491: 429-528.

van der Aalst, W. (1992). Timed coloured Petri nets and their application to logistics, PhD thesis, Eindhoven University of Technology.

van der Laan, E., Dekker, R., Salomon, M. \& Ridder, A. (1996). An (s, Q) inventory model with remanufacturing and disposal, International Journal of Production Economics 46-47: 339-350.

van der Laan, E. \& Salomon, M. (1997). Production planning and inventory control with remanufacturing and disposal, European Journal of Operational Research 102(2): 264-278.

Veleva, V. \& Ellenbecker, M. (2001). Indicators of sustainable production: framework and methodology, Journal of Cleaner Production 9(6): 519-549.

Viswanadham, N. \& Raghavan, N. R. S. (2000). Performance analysis and design of supply chains: a Petri net approach, Journal of Operations Research Society pp. 1158-1169.

Zimmermann, A. (2007). Stochastic Discrete Event Systems, Springer, Berlin Heidelberg New York.

Zimmermann, A., Knoke, M., Yee, S.-T. \& D.Tew, J. (2007). Model-based performance engineering of General Motors' vehicle supply chain, IEEE Int. Conf. on Systems, Man and Cybernetics (SMC 2007), Montreal, Canada, pp. 1415-1420. 


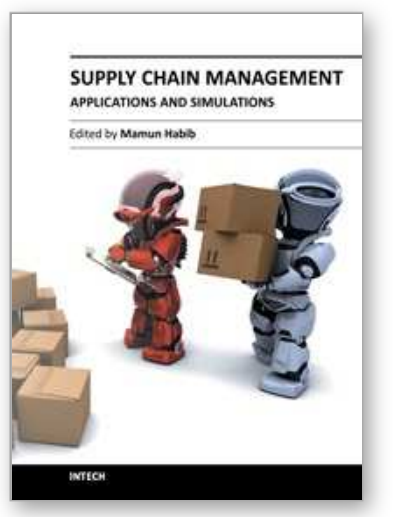

\author{
Supply Chain Management - Applications and Simulations \\ Edited by Prof. Dr. Md. Mamun Habib
}

ISBN 978-953-307-250-0

Hard cover, 252 pages

Publisher InTech

Published online 12, September, 2011

Published in print edition September, 2011

Supply Chain Management (SCM) has been widely researched in numerous application domains during the last decade. Despite the popularity of SCM research and applications, considerable confusion remains as to its meaning. There are several attempts made by researchers and practitioners to appropriately define SCM. Amidst fierce competition in all industries, SCM has gradually been embraced as a proven managerial approach to achieving sustainable profits and growth. This book "Supply Chain Management - Applications and Simulations" is comprised of twelve chapters and has been divided into four sections. Section I contains the introductory chapter that represents theory and evolution of Supply Chain Management. This chapter highlights chronological prospective of SCM in terms of time frame in different areas of manufacturing and service industries. Section II comprised five chapters those are related to strategic and tactical issues in SCM. Section III encompasses four chapters that are relevant to project and technology issues in Supply Chain. Section IV consists of two chapters which are pertinent to risk managements in supply chain.

\title{
How to reference
}

In order to correctly reference this scholarly work, feel free to copy and paste the following:

Gabriel Alves Jr., Paulo Maciel, Ricardo Lima and Fábio Magnani (2011). Business and Environment Performance Evaluation in Supply Chains: A Formal Model-Driven Approach, Supply Chain Management Applications and Simulations, Prof. Dr. Md. Mamun Habib (Ed.), ISBN: 978-953-307-250-0, InTech, Available from: http://www.intechopen.com/books/supply-chain-management-applications-and-simulations/businessand-environment-performance-evaluation-in-supply-chains-a-formal-model-driven-approach

\section{INTECH}

open science | open minds

\section{InTech Europe}

University Campus STeP Ri

Slavka Krautzeka 83/A

51000 Rijeka, Croatia

Phone: +385 (51) 770447

Fax: +385 (51) 686166

www.intechopen.com

\section{InTech China}

Unit 405, Office Block, Hotel Equatorial Shanghai

No.65, Yan An Road (West), Shanghai, 200040, China 中国上海市延安西路65号上海国际贵都大饭店办公楼405单元

Phone: +86-21-62489820

Fax: +86-21-62489821 
(C) 2011 The Author(s). Licensee IntechOpen. This chapter is distributed under the terms of the Creative Commons Attribution-NonCommercialShareAlike-3.0 License, which permits use, distribution and reproduction for non-commercial purposes, provided the original is properly cited and derivative works building on this content are distributed under the same license. 